\title{
EXPLORATORY FACTOR ANALYSIS OF THE CONTENTS AND STYLES OF IRRATIONAL THOUGHTS ASSESSED BY THE "ATTITUDES AND BELIEFS INVENTORY” (ABI)
}

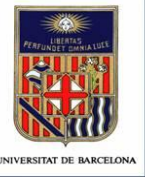

Ruiz, J., \& Fusté, A. ${ }^{a}$

$\therefore$ issip 201

${ }^{a}$ Department of Personality, Assessment and Psychological Treatment, University of Barcelona

${ }^{b}$ Spanish Association of Rational Emotive Behavior Therapy (Barcelona)

AETREC

INTRODUCTION \& PURPOSE

The aim of this study is to verify the factor structure of a back translated Spanish version (Lega, Caballo and Ellis, 2002) of the Attitudes and Beliefs

Inventory (ABI) (Burgess, 1990) developed from the perspective of Rational Emotive Behavior Therapy (REBT) by Albert Ellis.

The Spanish version of the ABI is a 48-items self-report inventory using a 5-point Likert scale that assesses rational and irrational attitudes and beliefs. 24-items cover two dimensions of irrationality:

a) areas of content (3 subscales: Affiliation/Approval [AA], Success/Perfectionism [SP], Comfort [C]), and

b) styles of thinking (4 subscales: Demandingness [D], Awfulizing/Catastrophizing [AC], Global Self-Rating [GSR], Low Frustration Tolerance [LFT]).

In addition, we analyze the reliability of the ABI's subscales (Cronbach's alpha) and the existence of gender differences in the content and/or styles of

irrational thinking.

\section{Paticipants}

250 university students (188 women and $62 \mathrm{men}$ ), aged between 19 and 75 years with a mean of 28.5 years $(S D=14.8)$ recruited from the High School of Public Relations (HSPR) and the Faculty of Psychology (PSY) of the University of Barcelona.

\section{DISTRIBUTION OF SAMPLE BY SEX \& STUDIES}

\begin{tabular}{|c|c|c|c|}
\hline Study/Sex & Men & Women & Total \\
\hline HSPR & $27(10,8 \%)$ & $80(32,0 \%)$ & $107(42,8 \%)$ \\
\hline PSY & $35(14,0 \%)$ & $108(43,2 \%)$ & $143(57,2 \%)$ \\
\hline Total & $62(24,8 \%)$ & $188(75,2 \%)$ & $250(100 \%)$ \\
\hline
\end{tabular}

The ABI scores are normally distributed in all scales $(p>0.05$ at Kolmogorov-Smirnov Test), except in D and GRS.

A one-way MANOVA was performed to verify if males and females were different in content and/or style of irrational thinking. All variables comply with Homocedasticity Test $(p>0,05)$.

\begin{tabular}{|c|c|c|c|c|c|}
\hline \multicolumn{6}{|c|}{ DESCRIPTIVES OF THE ABI SUBSCALES BY SEX } \\
\hline ABI & Total sample & Men & Women & F & $p$ \\
\hline AA & $\begin{array}{c}\text { Mean }=20,0 \\
(\text { Std. Dev. }=6,1)\end{array}$ & $\begin{array}{l}18,7 \\
(5,5)\end{array}$ & $\begin{array}{l}20,4 \\
(6,3)\end{array}$ & 3,843 & 0,051086 \\
\hline SP & $\begin{array}{r}24,8 \\
(5,2) \\
\end{array}$ & $\begin{array}{l}23,0 \\
(4,7) \\
\end{array}$ & $\begin{array}{l}25,4 \\
(5,2) \\
\end{array}$ & 10,670 & 0,001242 \\
\hline C & $\begin{array}{l}25,2 \\
(4,9) \\
\end{array}$ & $\begin{array}{l}24,2 \\
(5,1) \\
\end{array}$ & $\begin{array}{l}25,5 \\
(4,8) \\
\end{array}$ & 3,270 & 0,071770 \\
\hline $\mathbf{D}$ & $\begin{array}{l}23,5 \\
(3,7) \\
\end{array}$ & $\begin{array}{l}23,2 \\
(3,6) \\
\end{array}$ & $\begin{array}{l}23,6 \\
(3,8) \\
\end{array}$ & 0,493 & 0,483410 \\
\hline $\mathrm{AC}$ & $\begin{array}{c}17,1 \\
(5,0) \\
\end{array}$ & $\begin{array}{l}15,3 \\
(4,5)\end{array}$ & $\begin{array}{l}17,7 \\
(5,0) \\
\end{array}$ & 11,095 & 0,000997 \\
\hline GSR & $\begin{array}{l}11,5 \\
(4,1) \\
\end{array}$ & $\begin{array}{l}10,7 \\
(4,2) \\
\end{array}$ & $\begin{array}{l}11,7 \\
(4,1) \\
\end{array}$ & 2,824 & 0,094109 \\
\hline LFT & $\begin{array}{r}17,9 \\
(4,6)\end{array}$ & $\begin{array}{l}16,6 \\
(4,2)\end{array}$ & $\begin{array}{r}18,3 \\
(4,7)\end{array}$ & 6,314 & 0,012616 \\
\hline
\end{tabular}

Women scored significantly higher than men in $\mathrm{AC}(\boldsymbol{d}=-0.48)$ and LFT $(d=-0.37)$ styles. Also, in contents of SP $(d=-0.46)$

\section{Reliability indices}

\begin{tabular}{|c|c|c|c|c|c|c|c|}
\hline \multicolumn{10}{|c|}{ INTERNAL CONSISTENCY FOR THE ABI SUBSCALES } \\
\hline N=250 & AA & SP & C & D & AC & GSR & LFT \\
\hline No Items & 8 & 8 & 8 & 6 & 6 & 6 & 6 \\
\hline Mean & 19,99 & 24,80 & 25,18 & 23,48 & 17,12 & 11,49 & 17,86 \\
\hline Std. Dev. & 6,10 & 5,20 & 4,89 & 3,70 & 4,97 & 4,15 & 4,64 \\
\hline Cronbach's $\alpha$ & $\mathbf{0 , 8 1}$ & $\mathbf{0 , 7 2}$ & $\mathbf{0 , 7 2}$ & $\mathbf{0 , 6 7}$ & $\mathbf{0 , 8 1}$ & $\mathbf{0 , 6 6}$ & $\mathbf{0 , 7 6}$ \\
\hline Standardized $\alpha$ & $\mathbf{0 , 8 1}$ & $\mathbf{0 , 7 1}$ & $\mathbf{0 , 7 0}$ & $\mathbf{0 , 6 9}$ & $\mathbf{0 , 8 1}$ & $\mathbf{0 , 6 6}$ & $\mathbf{0 , 7 5}$ \\
\hline $\begin{array}{c}\text { Average inter- } \\
\text { item corr. }\end{array}$ & $\mathbf{0 , 3 6}$ & $\mathbf{0 , 2 4}$ & $\mathbf{0 , 2 3}$ & $\mathbf{0 , 2 8}$ & $\mathbf{0 , 4 2}$ & $\mathbf{0 , 2 5}$ & $\mathbf{0 , 3 4}$ \\
\hline
\end{tabular}

\section{Factor analdsis}

DETAILS OF THE EXPLORATORY FACTOR ANALYSIS (EFA)

Number of participants $(\mathrm{N})$

Number of variables (Items)

Procedure of determining the number dimensions

Dispersion Matrix

Method for Extraction

Method for Rotation

Determinant of the Matrix Bartlett's Statistic

Kaiser-Meyer-Olkin (KMO) Test

Factors with eigenvalues $>1$

Cum. Pct. of variance explained

Goodness of Fit Index (GFI)

Bentler's Simplicity Index (S)

Loading Simplicity Index (LS)

Root Mean Square of Residuals (RMSR)

Expected RMSR (Kelley's criterion)
250

24

Optimal Parallel Analysis (OPA)

Polychoric correlations

Unweighted Least Squares (ULS)

Promin

0,000051656596814

$2370,7(d f=276 ; p=0,000010)$ 0,86082

4

$53,37 \%$

0,99

0,80740

0,36194

0,0394

0,0634

(Style - Content)

i3 $($ LIT - C)

i4 (GSR - AA)

i7 (LFT-AA)

i8 (GSR - SP)

in (LFT - SP)

i12 $($ GSR - C $)$

iiz $(D-A A)$

i14 $(A C-S P)$

i1 $17(\mathrm{D}-\mathrm{SP})$

i18 $(\mathrm{AC}-\mathrm{C})$

i21 $(D-C)$

i22 $(A C-A A)$

i25 ( $-\mathrm{AA})$

i26 (AC - SP $)$

i29 $($ - SP)

i30 $(A C-C)$

i $34(\mathrm{AC}-\mathrm{AA})$

i39 (

i40 (GSR - AA)

i43( (LT - AA)

i44 (GSR - SP)

i47 ( (ITT-SP)

i48 (GSR - C)

INTER-FACIORS CORRELATIION MATRIX

\begin{tabular}{|c|c|c|c|c|}
\hline Factor & $F_{1}$ & $F_{2}$ & $F_{3}$ & $F_{4}$ \\
\hline$F_{1}$ & $\mathbf{1 . 0 0}$ & & & \\
\hline$F_{2}$ & $\mathbf{0 . 2 7}$ & $\mathbf{1 . 0 0}$ & & \\
\hline$F_{3}$ & 0.47 & 0.68 & 1.00 & \\
\hline$F_{4}$ & 0.50 & $\mathbf{0 . 3 3}$ & $\mathbf{0 . 4 4}$ & $\mathbf{1 . 0 0}$ \\
\hline
\end{tabular}

References attached to the back (jruizro@ub.edu)

\begin{tabular}{|c|c|c|c|}
\hline \multirow{6}{*}{$F_{1}$} & $\mathrm{~F}_{2}$ & $\mathrm{~F}_{3}$ & $F_{4}$ \\
\hline & & & 0.506 \\
\hline & 0.516 & & \\
\hline & 0.678 & & \\
\hline & 0.454 & & \\
\hline & & & $.25^{8}$ \\
\hline & 0.602 & & \\
\hline \multirow[t]{2}{*}{$0.5^{26}$} & 0.494 & & -.329 \\
\hline & 0.453 & & \\
\hline \multicolumn{4}{|l|}{0.714} \\
\hline & & & 0.563 \\
\hline \multirow[t]{2}{*}{0.620} & -.344 & & 0.339 \\
\hline & 0.704 & & \\
\hline \multirow[t]{2}{*}{$0.59^{8}$} & & & -.440 \\
\hline & & 0.754 & \\
\hline \multirow[t]{2}{*}{0.692} & & & \\
\hline & & 0.722 & \\
\hline \multirow{8}{*}{0.640} & -.378 & & \\
\hline & & 0.860 & \\
\hline & & & $0.5^{8} 7$ \\
\hline & 0.553 & & \\
\hline & 0.655 & & \\
\hline & 0.677 & & \\
\hline & & & 0.360 \\
\hline & $0.45^{8}$ & & \\
\hline
\end{tabular}

CONCLUSIONS

The EFA reproduced the main four styles of irrational thinking in relation with the three specific contents of irrational beliefs. However two factors ( $F_{2} \& F_{4}$ ) showed a complex configuration with important cross-loadings of different items in content and style, and moderate correlation inter-factors. Moreover most $\mathrm{ABI}$ subscales have low internal consistency. 


\title{
$\therefore$ issid 20 ï3Barcelona, July $22^{\text {nd }}-25$ th
}

\section{EXPLORATORY FACTOR ANALYSIS OF THE CONTENTS AND STYLES OF IRRATIONAL THOUGHTS ASSESSED BY THE “ATTITUDES AND BELIEFS INVENTORY” (ABI)}

\author{
Ruiz, J. ${ }^{a, b} \&$ Fusté, $A .^{a}$ \\ ${ }^{a}$ Department of Personality, Assessment and Psychological Treatment \\ University of Barcelona. \\ ${ }^{b}$ Spanish Association of Rational Emotive Behavior Therapy, Barcelona.
}

The factor structure of a back translated Spanish version (Lega, Caballo and Ellis, 2002) of the Attitudes and Beliefs Inventory (ABI) (Burgess, 1990) is analyzed in a sample of 250 university students.

The Spanish version of the ABI is a 48-items self-report inventory using a 5-point Likert scale that assesses rational and irrational attitudes and beliefs. 24-items cover two dimensions of irrationality: a) areas of content (3 subscales), and b) styles of thinking (4 subscales).

An Exploratory Factor Analysis (Parallel Analysis with Unweighted Least Squares method and Promin rotation) was performed with the FACTOR 9.20 software (Lorenzo-Seva and Ferrando, 2013).

The results reproduced the main four styles of irrational thinking in relation with the three specific contents of irrational beliefs. However, two factors showed a complex configuration with important cross-loadings of different items in content and style. More analyses are needed to review the specific content and style of such items.

\section{References}

Burgess, P.M. (1990). Toward Resolution of Conceptual Issues in the Assessment of Belief Systems in Rational-Emotive Therapy. Journal of Cognitive Psychotherapy: An International Quarterly, 4 (2), 171-184.

Lega, L. I., Caballo, V.E. \& Ellis, A. (2002). Teoría y práctica de la Terapia Racional EmotivoConductual. Madrid, Siglo XXI Eds.

Lorenzo-Seva, U. \& Ferrando, P.J. (February, 2013). Manual of the program FACTOR (v. 9.20). http://psico.fcep.urv.es/utilitats/factor/index.html. 